\title{
A TRANSFORMAÇÃO DAS TREVAS NA LITERATURA PRÉ-MODERNISTA
}

\author{
Sophia BEAL \\ Universidade de Minnesota (EUA) \\ sophiabeal@gmail.com
}

\begin{abstract}
Resumo: Este artigo aborda como a ideia de progresso enquanto eliminação das trevas emerge continuamente na renovação urbana e na literatura do Rio de Janeiro do início da década de 1900, particularmente no projeto de "bota-abaixo" do Prefeito Pereira Passos e na eletrificação da iluminação das ruas da cidade. Escritores recorrem à sugestiva tensão entre trevas e luz para explorar componentes simbólicos, morais, sociais e estéticos dos esforços de modernização do Rio de Janeiro. Retratos jornalísticos e ficcionais das transformações urbanas dessa cidade utilizam recursos literários tais como o antropomorfismo, hipérbole, ironia e fantasia para celebrar, questionar e desmistificar os projetos de iluminar melhor a capital. Por um lado, a iluminação elétrica das ruas tinha uma finalidade prática: tornar a locomoção noturna mais segura e fácil. Por outro, tinha uma finalidade estética: iluminar magnificentemente a cidade. Uma vez que representava tanto os ideais práticos quanto estéticos da reforma, a iluminação das ruas tornou-se uma sinédoque do esforço de modernização.
\end{abstract}

Palavras-chave: Lima Barreto. João do Rio. Olavo Bilac. Rio de Janeiro.

\begin{abstract}
This article focuses on how the idea of progress as the elimination of darkness continually arises in Rio de Janeiro's urban renewal and literature of the early 1900s, particularly with regard to Mayor Pereira Passos's bota-abaixo project and the electrification of the city's streetlights. Writers draw on the suggestive tension between darkness and light to explore symbolic, moral, social and aesthetic components of Rio de Janeiro's modernization efforts. Journalistic and fictional portrayals of Rio de Janeiro's urban transformations use literary devices such as anthropomorphism, hyperbole, irony and fantasy to celebrate, question and demystify efforts to better light the capital. On one hand, electric streetlight had a practical purpose: to make nighttime travel safer and easier. On the other, it had an aesthetic purpose: to dazzlingly illuminate the city. Since it represented both the practical and aesthetic ideals of the reform, streetlight became a synecdoche of the modernization effort.
\end{abstract}

Keywords: Lima Barreto. João do Rio. Olavo Bilac. Rio de Janeiro.

Em 1902, Francisco de Paula Rodrigues Alves (1848-1919) tomou posse como presidente do Brasil, e Francisco Pereira Passos (1836-1913) iniciou o mandato de prefeito da capital da nação. Uma difícil tarefa os aguardava. A capital conquistara uma má reputação. Enquanto as capitais nacionais vizinhas, como Buenos Aires e

\begin{tabular}{|l|l|l|l|l|}
\hline Pensares em Revista & São Gonçalo, RJ & n. 1 & $76-91$ & jul.-dez. 2012 \\
\hline
\end{tabular}


Montevidéu, já haviam sido atualizadas com importantes reformas urbanas, o Rio de Janeiro permanecia sendo um porto colonial provinciano. Os habitantes da cidade possuíam porcos, fazendeiros conduziam vacas de porta em porta vendendo leite e as vielas escuras e estreitas estavam repletas de atividades que lembrariam ao transeunte as fortes tradições rurais e africanas do Brasil (Cf. NEEDELL, 1987). Em resumo, o Rio em nada se assemelhava a Paris. E, em uma época em que Paris era o epicentro da cultura, isso era um problema. Além disso, os estrangeiros que viajavam para o Brasil optavam por entrar no país por outros portos para evitar o Rio de Janeiro, devido ao risco de ali contrair febre amarela. As ruas da capital despertavam sentimentos associados às trevas: desvio, crime, perigo, provação, caos, mistério e melancolia. As autoridades públicas, porém, queriam mudar essa associação. Queriam que os espaços públicos do Rio de Janeiro lembrassem a Cidade Luz e, portanto, fossem associados às qualidades que a luz evoca, tais como segurança, conhecimento, bondade, limpeza, frescor, modernidade, beleza, funcionalidade e esperança. Portanto, tais autoridades lançaram-se à conquista das trevas.

A ideia de progresso como a eliminação das trevas surge na literatura carioca no início da década de 1900. Retratos escritos das transformações urbanas do Rio de Janeiro utilizam recursos literários como antropomorfismo, hipérbole, ironia e fantasia para celebrar, questionar e desmistificar a iluminação pública instalada pela cidade. Escritores pré-modernistas recorrem à sugestiva tensão entre trevas e luz para explorar componentes simbólicos, morais, sociais e estéticos dos esforços de modernização do Rio de Janeiro.

Para Angel Rama (1996, p. 27-28), os letrados da América Latina, através de sua escrita, ordenam e interpretam a cidade material. Ao transformar objetos em significantes, os letrados atribuem sentido à cidade, construindo e controlando um ideal urbano. Este processo fica evidente em relatos jornalísticos do enorme projeto de renovação urbana conhecido como "bota-abaixo" (1902-1906), no qual os primeiros postes de luz elétrica da capital atuam como sinédoque de uma modernização ideal. Tais textos veem os primeiros postes de luz elétrica do Rio de Janeiro como prova de que a cidade progredira de um passado deplorável e começara um futuro glorioso. A clara demarcação de um "antes" e um "depois" estabelece uma ideia de ordem e melhoria através da iluminação pública.

\begin{tabular}{|l|l|l|l|l|}
\hline Pensares em Revista & São Gonçalo, RJ & n. 1 & $76-91$ & jul.-dez. 2012 \\
\hline
\end{tabular}


Para celebrar suas realizações como prefeito, Pereira Passos encomendou um guia turístico sobre o Rio de Janeiro. Ele narra a história das reformas como uma ruptura gloriosa com os aspectos sombrios do passado. Francisco Ferreira da Rosa escreveu o guia, que foi publicado em 1905. Ele atualizou o texto governamental em 1922, para celebrar os cem anos da independência brasileira. Ao descrever a cidade antes e depois das reformas no guia atualizado, o jornalista usa a iluminação elétrica para ilustrar a transformação total que Pereira Passos viabilizou durante seu mandato de quatro anos (1902-1906). Ferreira da Rosa diz que em "31 de Dezembro de 1902, Rio de Janeiro era uma Cidade estacionaria, sem atractivos, e de má fama no ponto de vista sanitario [. . .] Iluminação geral a gaz”, mas em "31 de Dezembro de 1906 Rio de Janeiro estava toda iluminada a electricidade", sugerindo que a luz tornou a cidade vibrante, limpa e moderna (1922, p. 29). Esta alegação, contudo, era falsa. Embora as ruas do centro fossem iluminadas por energia elétrica, os subúrbios que acompanhavam o trajeto da ferrovia Central do Brasil, começando no Engenho Novo, não eram dotados de nenhuma iluminação pública, nem mesmo os modelos mais antigos de gás ou óleo de baleia (Cf. DEPARTAMENTO DE RELAÇÕES, 1961). A afirmação exagerada do guia capta o desejo de que os postes de iluminação pública do Rio de Janeiro sintetizassem os investimentos estéticos e utilitários no espaço público, servindo assim como uma sinédoque da modernização. O prefeito Pereira Passos tratava os postes de iluminação de ferro em espiral como arte pública, fazendo parte de um embelezamento estratégico da cidade. Ele encomendou ao escultor brasileiro Rodolpho Bernardelli, que era diretor da Escola Nacional de Belas Artes, não apenas esculturas como também postes de iluminação para o centro renovado (Cf. COHEN, 2002). De acordo com tal investimento, as reformas extinguiriam as trevas reais e simbólicas de uma época anterior, substituindo-a por uma capital mais europeia, deslumbrante e ordenada.

Em uma crônica da edição de novembro de 1905 da revista ilustrada pró-governo Kósmos, Olavo Bilac (1864-1918) narra a inauguração recente da Avenida Central, que coroava o bota-abaixo de Pereira Passos e sediava os primeiros postes de luz elétrica do Rio de Janeiro. Bilac (1905) fala diretamente a um carrancismo personificado:

Inaugurou-se a Avenida! [...] Onde estás tú mettido, Carrancismo ignobil, que por tanto tempo nos opprimiste e deshonraste? [...] Andas, com certeza, homisiado nos beccos sujos, em que se mantém

\begin{tabular}{|l|l|l|l|l|}
\hline Pensares em Revista & São Gonçalo, RJ & n. 1 & $76-91$ & jul.-dez. 2012 \\
\hline
\end{tabular}


ainda a tradição do máu gosto e da immundicie: afugentou-te a luz da Avenida, horrorisou-te a alegria do povo, fulminou-te o despeito!

$\mathrm{O}$ autor apresenta dramaticamente a dicotomia bom/mau com uma série de palavras negativas para se referir à cidade anterior à reforma ("ignobil", "opprimiste", “deshonraste", "afugentou", "máu gosto" e "immundicie"). Ao metaforicamente purgar a cidade do mal, a luz da Avenida Central representa o oposto: limpeza, bom gosto, eficiência e ordem. A dinâmica estabelecida por Bilac é escrita de modo a camuflar certas complexidades da transformação urbana. Que aspecto retrógrado do Rio de Janeiro está sendo condenado a becos sujos? Quem deverá julgar o que constitui o bom gosto? Se a avenida iluminada simboliza o valor da cidade, de que modo tal valor é determinado? A linguagem florida de Bilac elide as estruturas de poder em jogo e os esforços autoritários da reforma para garantir que o centro fosse reservado à elite.

A mensagem persistente nesse elogio da eliminação das trevas é que a Avenida Central marcava a transição entre um deplorável e sombrio "antes" e um glorioso e iluminado "depois". Brito Boca (2004, p. 38) observa que os escritores da Belle Époque "superestimavam essa modernização da cidade, atribuindo ao Rio, em contos, romances e crônicas, ambientes e tipos que na realidade aqui não existiam”. No caso das representações da luz elétrica, porém, os escritores não estavam embelezando a realidade tanto quanto escolhendo fixar-se no tempo em vez de no espaço. A fixação com as luzes da Avenida Central centra o olhar do leitor em certas áreas da cidade e o distrai dos espaços públicos dos bairros pobres da capital. Isso significa que a única parte do Rio de Janeiro que importa para os letrados é o centro. Lima Barreto (18811922) e João do Rio (1881-1921) questionam essa concepção da cidade e insinuam a existência de dois pesos e duas medidas em uma jovem república teoricamente comprometida com a igualdade - um bastião liberal - mas, na prática, garantindo a dominação da elite.

$\mathrm{Na}$ crônica "Os humildes", de 1909 (incluída no volume Cinematographo: chronicas cariocas), João do Rio reflete sobre uma greve da época, de trabalhadores de uma empresa de gás. Ao fazê-lo, ele representa a "civilização" e o "conforto" do Brasil "pós-bota-abaixo" como características que não aparecem magicamente, mas devem, em vez disso, ser criadas pelos trabalhadores. Antonio Candido refere-se à crônica como "um dos escritos mais corajosos e lúcidos que um escritor brasileiro, não militante

\begin{tabular}{|l|l|l|l|l|}
\hline Pensares em Revista & São Gonçalo, RJ & n. 1 & $76-91$ & jul.-dez. 2012 \\
\hline
\end{tabular}


político, produziu sobre a situação do trabalhador" (CANDIDO, 1978, p. 199). Os acendedores de lampião e outros trabalhadores da empresa de gás paradoxalmente usam a escuridão para se tornarem visíveis: “de repente, só ao cruzar os braços, punha em sombra uma cidade inteira" (RIO, 1909, p. 194).

A crônica de João do Rio critica o Rio de Janeiro por excluir a classe trabalhadora dos benefícios da reforma urbana: "Quando pensou a cidade que havia, com efeito, por traz daquella sinistra fachada do Gaz, homens a suar, a sofrer, a morrer para lhe dar a luz que é civilização e conforto?” (RIO, 1909, p. 193). Enquanto representações anteriormente mencionadas da iluminação das ruas do Rio de Janeiro relacionam luz e civilização, João do Rio complica esse vínculo chamando a atenção para as pessoas marginalizadas pelo empreendimento "Rio civiliza-se", escurecendo a cidade como forma de protesto contra políticas tipicamente associadas ao "progresso", como manifestantes haviam feito durante a Revolta da Vacina de 1904, ao destruir postes de iluminação pública.

Embora a ampla Avenida Central tivesse sido concebida em parte para impedir revoltas sociais e barricadas (seguindo o modelo das reformas de Paris capitaneadas pelo Barão Georges-Eugène Haussmann), ela objetivava também controlar o acesso ao espaço público de outras maneiras. Lima Barreto, no romance de 1909, Recordações do escrivão Isaías Caminha, critica a exclusividade e a superficialidade do bota-abaixo, revelando como a conquista das trevas empreendida pelo governo possuía implicações raciais:

Os Haussmanns pululavam. Projetavam-se avenidas; abriam-se nas plantas squares, delineavam-se palácios, e, como complemento, queriam também uma população catita, limpinha, elegante e branca: cocheiros irrepreensíveis, engraxates de libré, criadas louras, de olhos azuis, com o uniforme como se viam nos jornais de moda da Inglaterra [...] (BARRETO, 1970, p. 148).

As reformas eram uma estratégia não apenas espacial, mas também social, de reconstrução do centro. Com humor e fúria, essa passagem ilustra a contribuição mais duradoura do filósofo Henri Lefebvre (1991) à teoria urbana, seu argumento de que o espaço urbano é tanto um produto quanto um produtor de relações sociais. Lima Barreto percebeu como o assim-chamado progresso implicava tornar a capital mais europeia, elitizada e branca, quando a maioria de sua população não se encaixava em nenhuma

\begin{tabular}{|l|l|l|l|l|}
\hline Pensares em Revista & São Gonçalo, RJ & n. 1 & $76-91$ & jul.-dez. 2012 \\
\hline
\end{tabular}


dessas categorias. Lima Barreto, assim, condena o desejo de embranquecer o Rio de Janeiro, controlar sua classe trabalhadora e concentrar os esforços na melhoria dos bairros ricos.

Lima Barreto atacava as reformas por serem investimentos na exclusão social, destinadas a embranquecer a área que constituía a principal porta de entrada do Brasil para comerciantes e visitantes. As reformas incluíam uma lei que proibia as pessoas de andar no Distrito Federal sem sapatos ou paletós, uma proibição que controlava quem tinha acesso ao espaço público (Cf. FISCHER, 2003). A fúria com que Lima Barreto descreve esta lei em Recordações do escrivão Isaías Caminha demonstra o quanto ele considerava as transformações urbanas discriminatórias.

A preocupação de Lima Barreto com a exclusão social permeia mais do que o conteúdo de sua escrita. Como observa Beatriz Resende (1993), Barreto tentava escrever em um estilo simples, que rejeitava a linguagem erudita em voga, para se conectar melhor com um público leitor mais amplo. Enquanto observava os espaços públicos de sua cidade tornarem-se cada vez mais socialmente excludentes, ele tentava combater a exclusão tornando sua escrita mais convidativa aos que eram letrados, mas dispunham de menor poder aquisitivo que o leitor padrão de jornal. Acreditando que a avenida era um projeto antidemocrático e historicamente insensível, Lima Barreto usou representações literárias da luz para defender seu argumento no folhetim anônimo intitulado O subterrâneo do Morro do Castelo, publicado no Correio da Manhã ao longo de cinco semanas em 1905, quando a Avenida Central estava sendo construída.

Em um capítulo desse folhetim, o narrador relata que, seguindo as instruções de Paulo de Frontin (1860-1933) - o engenheiro que chefiou a construção da Avenida Central -, luzes elétricas foram instaladas nas galerias do Morro do Castelo para facilitar a busca do ouro ali deixado pelos jesuítas. Assim, Lima Barreto ironicamente reposiciona os postes de luz elétrica da cidade - ele os coloca no subterrâneo. O paradoxo é evidente: durante décadas o governo fizera pouquíssimo esforço para suprir a falta de serviços públicos disponíveis nos cortiços, como o do Morro do Castelo; mas, dada a chance de obtenção de lucro, as autoridades rapidamente equiparam as entranhas do bairro com a moderna luz elétrica. Através dessa inversão imaginária, o autor ataca o elitismo das reformas e o padrão de erigir obras públicas para extrair recursos, e não para o bem público.

\begin{tabular}{|l|l|l|l|l|}
\hline Pensares em Revista & São Gonçalo, RJ & n. 1 & $76-91$ & jul.-dez. 2012 \\
\hline
\end{tabular}


Em $O$ subterrâneo, o protesto mais veemente é contra a destruição de monumentos históricos. Enfatizando a violência do ato, o folhetim descreve um dos engenheiros da Avenida Central, que

[...] pronunciou o Sésamo, abre-te naquela furna de Ali Babá; a sua picareta demolidora foi a varinha mágica que tirou o encanto do morro, despedaçando o modelo resistente, abatendo com fragor grandes moles de granito, levando a eletricidade irreverente ao soturno âmbito dos subterrâneos, onde a voz humana ecoa hoje, após três séculos de silêncio e paz, com o tom diabólico de profanação que teria a música de 'cake-walk' nas catacumbas de Roma (BARRETO, 1997, p. 85).

A diatribe - amplificada pelo excesso de metáforas que vão desde referências às Mil e uma noites ao catolicismo - sublinha a desonra moral da profanação do patrimônio em nome do lucro. O cake-walk, uma dança afro-americana popular no início dos anos 1900, seria obsceno nas catacumbas romanas devido ao seu estridente secularismo. A iluminação elétrica também é considerada obscena, pelo fato de invadir maliciosamente uma relíquia histórica. Além disso, o narrador imagina que os jesuítas mortos que escavaram o Morro do Castelo pensariam que ele foi "profanad[o] pelo progresso iconoclasta que deixa em sua passagem o cheiro acre do acetileno ou a claridade baça das lâmpadas elétricas" (BARRETO, 1997, p. 86). Lima Barreto emprega adjetivos incomuns para descrever a eletricidade: irreverente e baça. A eletricidade é irreverente por haver transgredido e desrespeitado as tradições locais, e é baça em sua uniformidade global. Longe de constituir um símbolo positivo de mudança, a luz elétrica é uma invasora desalmada e insensível aos monumentos históricos. O autor, portanto, contesta o uso oficial da palavra "progresso" com relação ao "botaabaixo", acusando as reformas de serem irresponsavelmente destrutivas.

Contrastando ainda mais com Bilac e Ferreira da Rosa, que enfatizavam o fato de a luz elétrica marcar a transição de um passado deplorável para um presente glorioso, Lima Barreto privilegia o espaço histórico do centro. Enquanto o governo queria que o olhar se fixasse adiante, Lima Barreto olha para trás - centenas de anos atrás, na verdade. O folhetim alterna entre 1709 e 1905, contando duas histórias sobre as galerias simultaneamente. Sua temporalidade é ainda mais porosa devido à crença de um dos personagens nas reencarnações fantásticas de políticos coloniais. Assim, Lima Barreto

\begin{tabular}{|l|l|l|l|l|}
\hline Pensares em Revista & São Gonçalo, RJ & n. 1 & $76-91$ & jul.-dez. 2012 \\
\hline
\end{tabular}


apresenta o centro como um palimpsesto que só pode ser compreendido pela sobreposição de vários momentos no tempo. Lefebvre (1991, p. 164) observa que espaço nenhum desaparece completamente, sem deixar traços. O subterrâneo insiste nesse ponto, enfatizando os vestígios históricos deixados pela demolição parcial do Morro do Castelo. Além disso, a preocupação de Lima Barreto com a rasura histórica envolvida nessa demolição parcial foi profética. O histórico Morro do Castelo foi destruído em 1921, paradoxalmente, para uma comemoração histórica: a Exposição Comemorativa do Centenário da Independência do Brasil de 1922. A cerimônia oferecia um pretexto para a destruição do desagradável cortiço, localizado bem no centro da capital. A feira de 1922 teve uma iluminação elétrica espetacular e serviu para exibir a cidade, tanto no Brasil como no exterior. Como demonstra esse incidente, luzes, espetáculo e modernização continuaram a servir de justificativa para remover cidadãos da classe trabalhadora do centro da cidade, tempos depois da primeira década do século $\mathrm{XX}$.

Uma exposição anterior, que ocorreu apenas três anos após a inauguração da Avenida Central, também exibiu uma iluminação magnífica, além de dar ao Brasil uma oportunidade de ostentar o sucesso de seus recentes esforços de saneamento e reforma urbana. O Brasil planejou a Exposição Nacional de 1908 na Praia Vermelha, no Rio de Janeiro de uma época em que sediar uma grande exposição era um rito de passagem necessário para uma nação se afirmar no cenário internacional. A exposição homenageava o centenário da abertura da América portuguesa aos navios das nações aliadas, que constituíra um passo inicial da independência brasileira. Como muitas feiras ao redor do mundo, a exposição foi marcada estrategicamente para uma importante data nacional, ressaltando o papel patriótico do evento, o de cultivar um espírito de nacionalismo (Cf. HARDMAN, 1988). A iluminação era uma das características distintivas desta exposição, com a qual "a novíssima República superou em pompa, neoclassicismo e luzes brilhantes os eventos similares do velho mundo" (HARDMAN, 1988, p. 113). Por mais de uma década, a eletricidade desempenhara um papel central nas feiras mundiais, fornecendo uma demonstração de ciência e espetáculo.

Desde a Exposição Colombiana de Chicago de 1893, a elaborada iluminação elétrica das feiras representava particularmente o poder de uma nova era científica de

\begin{tabular}{|l|l|l|l|l|}
\hline Pensares em Revista & São Gonçalo, RJ & n. 1 & $76-91$ & jul.-dez. 2012 \\
\hline
\end{tabular}


eletricidade, que transfigurava a noite de um modo que parecia desafiar a natureza (Cf. GUNNING, 1994). A crônica de João do Rio, "Noturno policromo”, de 1908 (incluída na antologia de 1909 intitulada Cinematographo: chronicas cariocas), procura conciliar a experiência visual da Exposição Nacional com uma representação verbal igualmente deslumbrante da iluminação elétrica da feira. Ao elogiar a feira por suas luzes e sua aparência, a crônica concebe a modernidade brasileira principalmente em termos de seus componentes espetaculares, agradáveis, não-racionais, teatrais e estéticos. A Exposição Nacional sintetizava esses aspectos da modernidade, à medida que retratava uma cidade efêmera (que seria desmantelada) dentro de uma cidade. "Noturno" capta o teor de encenação da modernidade do Rio de Janeiro: uma imagem bela, fascinante e suntuosa, com pouco conteúdo atrás de sua fachada.

O texto de João do Rio enquadra-se em um gênero de crônicas de jornal da virada do século que retratam novas e específicas formas de tecnologia como emblemas da modernidade. Exemplos famosos dentro desse gênero incluem o texto de José Martí de 1883, "El Puente de Brooklyn”, e as crônicas de Rubén Darío sobre a Exposição de Paris de 1900. Uma característica recorrente nesse gênero é o uso de linguagem ornamentada e estilizada, que transmite emoções, detalhes sensoriais e estado de espírito, muito mais do que informações práticas sobre a tecnologia descrita. Como entender esta abordagem (estilizada e contrária à informação) da escrita sobre os emblemas tecnológicos da modernidade, que vai contra a tendência dos jornais da época de noticiar fatos? Em um momento em que a racionalidade (maquinaria mais eficiente, transporte mais rápido, ruas mais ordenadas, limites mais claros nos espaços públicos e assim por diante) estava sendo privilegiada na América Latina, Julio Ramos (2011, p. 116) postula que a crônica de jornal estilizada afirmava a autonomia da arte sobre o utilitarismo.

A linguagem florida da crônica distanciava-se dos usos da linguagem relacionados à eficiência, à utilidade e à divulgação de informações (linguagem burocrática, notícias factuais, instruções etc.). Ao adotar o que Ramos chama de uma estética do luxo ou do excesso, tais crônicas confirmam que a linguagem deve ser mais do que apenas um veículo para expressar informações úteis de forma eficiente (Cf. RAMOS, 2001, p. 116). A representação estilizada das luzes da feira em "Noturno" - que envolve personificação, metáfora, hipérbole, detalhes sensoriais e um toque de fantástico -

\begin{tabular}{|l|l|l|l|l|}
\hline Pensares em Revista & São Gonçalo, RJ & n. 1 & $76-91$ & jul.-dez. 2012 \\
\hline
\end{tabular}


fornece um exemplo do uso que a crônica faz da linguagem para transmitir a maravilha da eletricidade, não sua funcionalidade:

\begin{abstract}
A luz vestia inteiramente os pavilhões de fulgores de sol, tauxeava d'oiro os palacios, punha vibrações de labareda no ambiente, espelhava no céo um opaco reflexo de chama enorme, mergulhava na agua baloiçante da enseada e como que repercutia além, para fóra, para o outro lado, por todo o caes, pela cidade a dentro, ardendo em outras mil lampadas ardentes (RIO, 1909, p. 377).
\end{abstract}

Cada frase retrata as luzes da exposição usando uma metáfora diferente, criando um efeito sensorial cumulativo ao associar sons e movimentos à luz. A torrente verbal excessiva aproxima-se da sensação de perplexidade, variedade e sublimidade provocada pela própria feira. As sensações eram versões mais intensas da experiência da vida urbana moderna, com suas propagandas que distraem a atenção, seus estímulos visuais, suas ruas movimentadas e sua velocidade aumentada.

A crônica desassocia a luz elétrica da tecnologia, da invenção e da racionalidade ao enfatizar a ligação da fonte da luz ao mito grego e ao cosmos. O companheiro do narrador declara com fervor:

O mito de Prometheu descobrindo o fogo perpetua-se e hoje todos os progressos humanos grandiosos anunciam-se pela alegria da luz.

Nunca viste illuminar-se a Exposição? É o anuncio aos astros de que aqui ficou um pedaço do sol (RIO, 1909, p. 375).

A escolha de recorrer ao antigo, mítico e cósmico para representar a luz elétrica afirma o lugar do não-racional na modernização brasileira. Tal escolha sinaliza que, enquanto os engenheiros estão preparados para melhorar a utilidade da luz elétrica, os artistas estão preparados para expressar sua maravilha. Além disso, a estilização da crônica enfatiza que a tecnologia, a engenharia e os bens associados à modernidade têm propósitos não-utilitários (expressando harmonia, força, beleza e unidade) que a arte está bem equipada para transmitir. As crônicas de jornal estilizadas do período insistem nos aspectos não-utilitários da modernização, usando uma linguagem decididamente não-utilitária para fazê-lo.

O título da crônica evoca a variedade sensorial da feira e, por sua vez, da modernidade. Um noturno refere-se tanto a uma pintura de uma cena noturna quanto a

\begin{tabular}{|l|l|l|l|l|}
\hline Pensares em Revista & São Gonçalo, RJ & n. 1 & $76-91$ & jul.-dez. 2012 \\
\hline
\end{tabular}


uma composição musical que transmite uma atmosfera de sonho. O texto de João do Rio sugere que o espetáculo de ver a feira acesa à noite é uma experiência artística e espiritual. $\mathrm{O}$ amigo tenta convencer o relutante narrador a ficar mais tempo para ver as luzes do pavilhão acesas ao entardecer, argumentando que "tua tristeza passará, os nervos cançados se galvanisarão" (RIO, 1909, p. 375). Acreditava-se que a eletricidade trazia benefícios para a saúde. Os médicos da época achavam que a eletricidade fornecia nutrição para nervos exauridos (Cf. SIMON, 2004), e a eletricidade era vista como uma espécie de vitamina que era um meio de restauração de energias exauridas (Cf. SCHIVELBUSCH, 1988). A proclamação da crônica põe em colapso a linguagem da publicidade, o empreendimento de uma grande mostra e a qualidade sublime de presenciar a beleza estética, como que sugerindo que o fascínio da modernização do Rio de Janeiro derivava da combinação dessas forças.

Em "Noturno", a eletricidade parece ter uma voz, um recurso literário que tem o efeito de expandir o impacto sensorial da luz. João do Rio refere-se ao "gong de luz" e às orquestras, bandas militares e gritos esparsos da multidão que "pareciam as vozes de todas aquellas luzes” (RIO, 1909, p. 377; 380). Assim, ele apela para os apetites auditivo e visual dos leitores, que haviam sido apresentados recentemente às vitrolas e aos filmes. Como observa Flora Süssekind, João do Rio encantava-se com técnicas e invenções modernas, e estava "[c]onsciente, inclusive, da violenta transformação no próprio ‘modo de olhar' que operavam então” (SÜSSEKIND, 1987, p. 45).

Ao escrever sobre a iluminação da Exposição Nacional como um fenômeno primariamente estético (a luz recobre uma área da cidade com um resplendor de beleza), a crônica privilegia os componentes estéticos e superficiais da urbanização, em vez de mudanças substanciais. Enquanto a ficção de Lima Barreto sugere que as melhorias urbanas deveriam ser distribuídas de modo mais igualitário, "Noturno" sugere que o progresso do Rio de Janeiro pode ser medido por um único evento espetacular na cidade: "Dessa apoteose de vitral magico como que nascia todo o esplendor da Cidade Maravilha” (RIO, 1909, p. 379). Assim como a descrição de Olavo Bilac dos postes de iluminação pública da Avenida Central, o que está implícito é que uma poderosa demonstração do progresso do Rio de Janeiro pode influenciar toda a capital ao inspirar assombro, uma postura que afirma o valor simbólico da iluminação grandiosa e da pompa da República.

\begin{tabular}{|l|l|l|l|l|}
\hline Pensares em Revista & São Gonçalo, RJ & n. 1 & $76-91$ & jul.-dez. 2012 \\
\hline
\end{tabular}


A eliminação das trevas envolveu tanto os componentes práticos quanto estéticos da iluminação urbana. No entanto, seu oposto - o louvor das sombras urbanas - também possuía bases práticas e estéticas. João do Rio reconhecia o fascínio dos saqueadores da meia-noite e, em sua escrita, os lugares escuros e os vadios que os percorriam continuavam a assombrar o Rio de Janeiro muito tempo depois do advento dos primeiros postes de iluminação elétrica. Renato Cordeiro Gomes observa que João do Rio, no "papel de flâneur já dimensionado em repórter, registra o que a cidade idealmente planejada pelos donos do poder despreza, quer destruir e rejeitar como lixo" (GOMES, 1994, p. 146). O que vemos ao longo da obra de João do Rio e Lima Barreto é o quanto o indesejável estava associado com (ou regulado por) as trevas. Em seu texto "A rua" - sobre o prazer de perambular pelas ruas do Rio de Janeiro prestando atenção à sua personalidade, história e pedestres -, João do Rio capta como as ruas do Rio de Janeiro exibiam a conquista das trevas e também seu oposto. O autor escreve que a rua fornece à pessoa civilizada "luz, luxo, bem-estar, comodidade [...]", características que eram prioridades do esforço de modernização (RIO, 1997, p. 48). No entanto, o espaço público também oferece o oposto disso, como sugere João do Rio na seguinte personificação da rua: “A rua é generosa. $\mathrm{O}$ crime, o delírio, a miséria não os denuncia ela" (1997, p. 47). Enquanto o "bota-abaixo" desprezava tais características, para João do Rio elas são os ingredientes de uma boa história. Ele encontrava nas trevas urbanas as perversões, os crimes, os mistérios e paixões centrais ao apelo de sua ficção. Em nenhum texto isso é tão bem exemplificado como no conto "O bebê de tarlatana rosa", incluído na compilação de João do Rio - de 1910 - intitulada Dentro da noite.

Em "O bebê", um boêmio rico, em uma festa em uma mansão no Rio de Janeiro, conta uma história - que ele alega ser verdadeira, embora o leitor não tenha nenhuma confirmação disso - sobre uma experiência que viveu no fim do carnaval. Sua representação do que acontece nas ruas do Rio de Janeiro constitui o oposto da campanha contra as trevas do "bota-abaixo": festividade caótica, violência física, feiura, pobreza, negritude, tradição afro-brasileira, luxúria, grotesco e desordem. Ele considera que esses elementos - o oposto de uma concepção da elite carioca de luxo e progresso irão capturar a atenção de sua plateia porque contrastam agudamente com as concepções então dominantes do que era bom, civilizado e ordenado. Ele narra ter saído em busca do que parecia ser o carnaval autêntico dos afro-brasileiros pobres, encontrando naquele

\begin{tabular}{|l|l|l|l|l|}
\hline Pensares em Revista & São Gonçalo, RJ & n. 1 & $76-91$ & jul.-dez. 2012 \\
\hline
\end{tabular}


ambiente uma mulher fantasiada de bebê que usava um nariz falso. $\mathrm{O}$ amigável flerte entre os dois desanda quando o narrador arranca o falso nariz da mulher em uma viela escura - e, em resposta ao seu rosto fisicamente deformado (ela não tem nariz), espanca-a e abandona-a. Se o ataque fora supostamente dirigido a uma feiura ofensiva, também fora dirigido a uma afro-brasileira pobre. Entendida alegoricamente, sua ação é semelhante às reformas urbanas, que eram pretensamente um ataque à feiura da cidade, mas implicitamente envolviam um ataque à sua população pobre e afro-brasileira.

O termo "progresso" sintetizava um conjunto de ideais mantidos pelo grupo social dominante - uma definição que, como vimos, foi contestada por alguns escritores. O assim-chamado progresso incluía práticas, como: a adoção de costumes europeus; o embranquecimento da população via imigração europeia; o asseguramento da dominação da classe alta; a melhoria da indústria e outros métodos para fazer do Brasil um parceiro comercial mais atraente. Escritores pré-modernistas mostraram como, através de uma reconfiguração do espaço público da cidade, o novo regime republicano - que estivera no poder desde a queda do Império em 1889 - implantou seus ideais de progresso e civilização. As reformas afirmavam um desejo de "civilizar" o Rio de Janeiro, ao reservar seus espaços públicos para a elite.

À medida que retratavam as transformações sofridas pelo Rio de Janeiro, os escritores perceberam como a iluminação elétrica das ruas - uma síntese de arte, tecnologia e utilidade - simbolizava o tipo de progresso que o governo buscava. $\mathrm{O}$ governo esperava que o brilho constante das lâmpadas de arco da Avenida Central erradicasse tanto a escuridão simbólica como real de uma cidade atrasada no tempo. Enquanto alguns cronistas da Belle Époque, como Bilac e Ferreira da Rosa, usaram o jornalismo para cumprir a missão de celebrar a recém-conquistada beleza do Rio de Janeiro, outros, como Lima Barreto, procuravam revelar elementos mais sinistros ocultos atrás das luzes. João do Rio, por sua vez, possuía sentimentos mais ambivalentes sobre o investimento do governo em seus espaços públicos; ele não era nem tão subserviente quanto Bilac e Ferreira da Rosa, nem tão reacionário quanto Lima Barreto. Além disso - com exceção de Lima Barreto, que era conhecido por suas brigas com jornais - a maioria das crônicas sobre as reformas provavelmente foram influenciadas pelas inclinações políticas dos jornais para os quais os escritores trabalhavam. Os

\begin{tabular}{|l|l|l|l|l|}
\hline Pensares em Revista & São Gonçalo, RJ & n. 1 & $76-91$ & jul.-dez. 2012 \\
\hline
\end{tabular}


elogios de Olavo Bilac e Ferreira da Rosa asseguraram a ambos a estabilidade no emprego, escrevendo para publicações governistas (GOMES, 1994, p. 107).

Um exame dos primórdios da iluminação elétrica do Rio de Janeiro, bem como do interesse da Belle Époque na iluminação urbana, capta tanto os aspectos estéticos como práticos dessa renovação urbana liderada pelo Estado que envolvia associações entre luz e progresso. Utilizando a hipérbole, a personificação e outras técnicas literárias, escritores pré-modernistas enfatizaram como as reformas do Rio de Janeiro, em particular a iluminação elétrica, simbolizavam um certo tipo de modernização, com implicações sobre o patrimônio histórico, estética, raça, classe e geografia física da cidade. Os escritores, assim, desmistificaram - ou mistificaram ainda mais - os esforços de modernização do governo, trazendo à tona o que era significativo, maravilhoso e problemático sobre as transformações da capital.

\section{Referências bibliográficas:}

BARRETO, Afonso Henriques de Lima. Recordações do escrivão Isaías Caminha. 4. ed. São Paulo: Brasiliense, 1970.

BARRETO, Afonso Henriques de Lima. O subterrâneo do Morro do Castelo. 2. ed. Rio de Janeiro: Dantes, 1997.

BILAC, Olavo. Chronica. Kósmos, n. 11, Rio de Janeiro, Fundação Biblioteca Nacional, 1905.

BROCA, Brito. A vida literária no Brasil: 1900. 4. ed. Rio de Janeiro: José Olympio, 2004.

CANDIDO, Antonio. Radicais de Ocasião. Revista Discurso, n. 9, São Paulo, Departamento de Filosofia da FFLCH da USP, nov. 1978, p. 193-201.

COHEN, Alberto A.; FRIDMAN, Sergio A. Rio de Janeiro ontem e hoje. 8. ed. Rio de Janeiro: Amazon, 2002.

DEPARTAMENTO DE RELAÇÕES PÚBLICAS RIO LIGHT. Histórico do desenvolvimento do Sistema Rio 1905-1960. Rio de Janeiro: Rio Light S. A., 1961.

FISCHER, Augusto Luís. Parnasianismo brasileiro: entre ressonância e dissonância. Porto Alegre: EDIPUCRS, 2003.

FREYRE, Gilberto. Ordem e progresso: v. 2. 2. ed. Rio de Janeiro: José Olympio, 1962.

\begin{tabular}{|l|l|l|l|l|}
\hline Pensares em Revista & São Gonçalo, RJ & n. 1 & $76-91$ & jul.-dez. 2012 \\
\hline
\end{tabular}


GOMES, Renato Cordeiro. Todas as cidades, a cidade. Rio de Janeiro: Rocco, 1994.

GUNNING, Tom. The world as object lesson: cinema audiences, visual culture and the St. Louis World's Fair, 1904. Film History, n. 6.1, 1994, p. 422-44.

HARDMAN, Francisco Foot. Trem fantasma: a ferrovia Madeira-Mamoré e a modernidade na selva. 2. ed. São Paulo: Companhia das Letras, 2005. 1988.

LEFEBVRE, Henri. The production of space. Massachusetts: Blackwell, 1991.

MAGALHÃES, Gildo. Força e luz: eletricidade e modernização na República Velha. São Paulo: Editora UNESP, 2000.

NEEDELL, Jeffrey. A tropical belle époque: elite culture and society in turn-of-thecentury Rio de Janeiro. New York: Cambridge University, 1987.

RAMA, Angel. The lettered city. Durham: Duke University, 1996.

RAMOS, Julio. Divergent modernities: culture and politics in nineteenth-century Latin America. Durham, North Carolina: Duke University, 2001.

RESENDE, Beatriz. Lima Barreto e o Rio de Janeiro em fragmentos. Rio de Janeiro: Editora Universidade Federal do Rio de Janeiro, 1993.

RIO, João do. A alma encantadora das ruas. São Paulo: Companhia das Letras, 1997.

RIO, João do. Cinematographo: chronicas cariocas. Porto: Editores Livraria Chardron, 1909.

RODRIGUES, João Carlos. João do Rio: catálogo bibliográfico 1899-1921. Rio de Janeiro: Biblioteca Carioca, 1994.

ROSA, Francisco Ferreira da. Rio de Janeiro: noticia historica e descritiva da capital do Brasil. Rio de Janeiro: Annuario do Brasil, 1922.

SCHIVELBUSCH, Wolfgang. Disenchanted night: the industrialization of light in the nineteenth century. Berkeley: University of California, 1988.

SEVCENKO, Nicolau. Literatura como missão: tensões sociais e criação cultural na Primeira República. 2. ed. São Paulo: Companhia das Letras, 2003.

SIMON, Linda. Dark light: electricity and anxiety from the telegraph to the x-ray. Orlando: Harcourt, 2004.

SÜSSEKIND, Flora. Cinematógrafo de letras: literatura, técnica e modernização no Brasil. São Paulo: Companhia das Letras, 1987.

\begin{tabular}{|l|l|l|l|l|}
\hline Pensares em Revista & São Gonçalo, RJ & n. 1 & $76-91$ & jul.-dez. 2012 \\
\hline
\end{tabular}


Recebido em: 24 de julho de 2012.

Aprovado em: 15 de outubro de 2012.

\section{Sobre a autora:}

Professora Assistente do Departamento de Estudos Espanhóis e Portugueses da Universidade de Minnesota. De 2010 a 2012, foi bolsista de Pós-Doutorado pela Fundação Mellon no Departamento de Espanhol e Português da Tulane University. PhD em Estudos Portugueses e Brasileiros pela Brown University (2010). Seu trabalho recente aborda questões relativas ao espaço público e ao desenvolvimento urbano na ficção brasileira. 